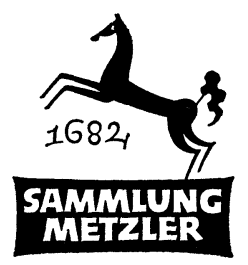

REALIENBÜCHER FÜR GERMANISTEN ABT. D:

LITERATURGESCHICHTE 
HANS JOORG SANDKUHLER

\section{Friedrich Wilhelm Joseph Schelling}

MCMLXX

J. B. METZLERSCHE VERLAGSBUCHHANDLUNG STUTTGART 
M 87

ISBN 978-3-476-10087-O

ISBN 978-3-476-03821-o (eBook)

DOI 10.1007/978-3-476-03821-o

(C) Springer-Verlag GmbH Deutschland 1970

Ursprünglich erschienen bei J. B. Metzlersche Verlagsbuchhandlung und Carl Ernst Poeschel Verlag GmbH in Stuttgart 1970 


\section{VORBEMERKUNG}

Erkenntnis oder Interesse: Die Qual dieser Wahl gehört zur Tradition der philosophischen Wissenschaft. Als Alternative ist sie nicht akzeptabel. Hier sei sie mit Nachdruck verworfen. Denn die Erkenntnis der Antinomie von Theorie und Praxis verrät Interesse, denn die Erkenntnis der Einheit von Theorie und Praxis verdankt sich Interesse. Das Dasein des bürgerlichen Theoretikers Schelling ist von der gesellschaftlichen Praxis der bürgerlichen Revolution nicht abzulösen. Das ist gültig auch für seine Interpreten. Weil „es nicht das Bewußtsein der Menschen ist, das ihr Sein, sondern umgekehrt ihr gesellschaftliches Sein, das ihr Bewußtsein bestimmt", ist dieser Text zu Schelling Lukács zu folgen - nicht ohne Parteilichkeit. Gewiß ist er deshalb nicht auch schon tendenziös, schließt vielmehr Selbstkritik ein gegenüber Methode und eigenem Standpunkt.

Diese Sammlung von Materialien zur Philosophie Schellings wurde für Literaturwissenschaftler geschrieben. Sie bietet sich zugleich dem Philosophiehistoriker an. Literatur, Kunst und Philosophie des 19. Jhs. sind insgesamt Signaturen eines Prozesses, der abstrakt als gesellschaftlicher Strukturwandel, konkret als sozioökonomische und ideologische Ausbildung und Vollendung der bürgerlichen Gesellschaft zu beschreiben ist. Schellings Aktualität ist ein unübersehbares Indiz dafür, daß er noch nicht abgeschlossen und sein Ende nur utopisch zu sichten ist. Die Schelling'sche Philosophie verdient heutiges hermeneutisches Interesse; sie trägt bei zur Erkenntnis und Kritik der geschichtlichen Bedingungen der Gegenwart. 


\section{INHALT}

Handschriften, Werke, Ausgaben, Briefe . . . . . . . . I

Zur Lage der Schelling-Forschung . . . . . . . . . . . . . . 8

Methodische Grundfragen . . . . . . . . . . . . . 8

Schelling-Bibliographie 1954-1969. . . . . . . . 24

Schellings Philosophie und die politische, sozio-ökonomische und ideologische Wirklichkeit $\mathrm{zw}$ ischen 1770 und $\mathrm{r} 860$. . . . $4 \mathrm{I}$

Wichtige historische Daten zwischen 1770 und 1860 . . . . 47

Synopse wichtiger symptomatischer Werke der Philosophiegeschichte und Literaturgeschichte aus den Jahren 1770-1860

Schellings Leben . . . . . . . . . . . . . . 62

Schellings philosophisches Werk . . . . . . . . . 8I

Zur Frage der Periodisierung des Werkes . . . . . . . . 8 $\mathrm{r}$

Schellings Idealismus und die Klassische Deutsche Philosophie 84

Literatur zu verschiedenen Aspekten im Werk Schellings . . 87

Die Philosophie der Kunst . . . . . . . . . . . . . . 990

Register ................ I06 


\section{Sigeln UND ABKüRZUNGen}

AfGP Archiv für Geschichte der Philosophie (Berlin)

AfP Archiv für Philosophie (Stuttgart)

ARS Archiv für Rechts- und Sozialphilosophie (Berlin)

AP Archives de Philosophie (Paris)

DZP Deutsche Zeitschrift für Philosophie (Berlin/DDR)

Jb. Jahrbuch

Kst. Kantstudien (Berlin; NF Köln)

LThK Lexikon für Theologie und Kirche. Hrsg. v. J. Höfer u. K. Rahner. ${ }^{2} 1964$

MEW Karl Marx/Friedrich Engels, Werke. Hrsg. v. Institut für Marxismus-Leninismus beim ZK der SED. 39 Bde und ein Ergänzungsband in 2 Teilen. (Berlin/DDR), 1956-1968.

Mh. Monatshefte

PRdsch. Philosophische Rundschau (Tübingen)

PJ Philosophisches Jahrbuch der Görres-Gesellschaft (Fulda)

RGG Religion in Geschichte und Gegenwart. Handwörterbuch für Theologie und Religionswissenschaft. Hrsg. v. K. Galling. ${ }^{3}$ I961

RMM Revue de Métaphysique et de Morale (Paris)

Sch. Scholastik. Vierteljahrsschrift für Theologie und Philosophie (Freiburg/Brsg.)

StP Studia philosophica. Jahrbuch der schweizerischen philosophischen Gesellschait (Basel)

ZKT Zeitschrift für Katholische Theologie

ZPF Zeitschrift für philosophische Forschung (Meisenheim/Glan)

ZRG Zeitschrift für Religions- und Geistesgeschichte

ZThK Zeitschrift für Theologie und Kirche 